Artigo

\title{
Aplicação de Análises de Ondaletas para Detecção de Ciclos e Extremos Pluviométricos no Leste do Nordeste do Brasil
}

\author{
Djane Fonseca da Silva \\ Instituto de Ciências Atmosféricas da Universidade Federal de Alagoas, Maceió, AL, Brasil.
}

Recebido em 13 de Maio de 2015 - Aceito em 19 de Novembro de 2016

\begin{abstract}
Resumo
O presente artigo tem como objetivo identificar ciclos de extremos pluviométricos e de suas causas através das escalas temporais detectadas em séries de precipitação para as capitais do leste do Nordeste do Brasil. Para tanto, foram usados dados pluviométricos diários das capitais dos estados que compõem o leste do NEB com períodos em comum de 1961-2014 submetidos à Ondaleta Morlet. Todas capitais apresentaram a escala entre 1 e 2 anos, a escala de aproximadamente 7 anos, a escala de 11 anos, e a escala temporal de 20,2-22 anos. Com a aplicação da Análise de Ondaledas foram identificados anos com eventos/precipitações extremas e supõe-se como causas climáticas: sazonalidade, variabilidade interanual, ENOS, Dipolo do Atlântico, Manchas Solares e Oscilação Decadal do Pacífico. A forte influência do Oceano Atlântico e de seu Dipolo esteve presente em todas as séries de Precipitação de todas cidades estudadas.
\end{abstract}

Palavras-chave: escalas temporais, Morlet, Dipolo do Atlântico, ODP, ENOS.

\section{Wavelet Analysis Applied for the Detection of Cycles and Extreme Rainfall in East of Northeast Brazil}

\begin{abstract}
The current article has aimed to identify cycles of rainfall extremes and their causes through of timescales detected in rainfall series for the capitals of eastern Northeast Brazil. Therefore, was used daily rainfall data from the capitals of the states that make up the eastern NEB with periods in common of 1961-2014 submitted to Morlet wavelet. All capital presented the scale between 1 and 2 years, the range of about 7 years, scale of 11 years and time scale from 20.2 to 22 years. With the application of Wavelet analysis were identified years with events / extreme rainfall and it is supose as climate causes: Seasonality, Interannual variability, ENSO, Dipole Atlantic, Sunspots and the Pacific Decadal Oscillation. The strong influence of the Atlantic Ocean and its Dipole was present in all rainfall series of all cities studied.
\end{abstract}

Keywords: timescales, Morlet, Dipole Atlantic, PDO, ENSO.

\section{Introdução}

Diversos estudos (IPCC, 2007; IPCC, 2010; Da Silva et al., 2014; Santos et al., 2011; IPCC, 2014) indicam que a variabilidade climática atual, com tendência para o aquecimento global, está associada a um aumento de extremos climáticos. Nesta situação, os eventos de temporais/chuvas intensas ou de estiagens severas, entre outros, podem tornar-se mais frequentes, aumentando a possibilidade de incidência de desastres naturais.

A maioria dos desastres no Brasil (mais de 80\%) está associada a eventos extremos e às instabilidades atmosfé- ricas severas, que são responsáveis pelo desencadeamento de inundações, vendavais, escorregamentos etc. Com relação à distribuição espacial, mais de $60 \%$ dos casos ocorreram nas regiões Sudeste e Sul, ficando o Nordeste do Brasil (NEB) em $2^{\circ}$ lugar nesse ranking (Marcelino, 2008). Ressalta-se que Marcelino (2008) não utilizou uma metodologia universal de classificação para desastres de enchentes e secas e isto pode ter superestimados os desastres de enchentes e subestimados os de secas.

A minimização ou redução do impacto dos desastres dá-se através de medidas preventivas que podem ser classificadas em estruturais e não estruturais. As medidas estru-

Autor de correspondência: Djane Fonseca da Silva, djane.silva@icat.ufal.br. 
turais são aquelas de cunho corretivo, como as obras de engenharia. As não-estruturais, de caráter educativo, apesar dos resultados a médio e longo prazo, são de baixo custo, de fácil implementação e permite uma correta percepção do risco. Como exemplo, destacam-se os mapeamentos, as análises de vulnerabilidade, os zoneamentos das áreas de risco e a educação ambiental (NCEM, 1998; Andjelkovic, 2001; ISDR, 2002). Para tanto, é necessário conhecer as causas ou o que desencadeou o desastre, para assim, definir as medidas preventivas que serão adotadas.

Desta forma, a detecção das causas de ciclos e extremos pluviométricos, os quais resultam em desastres naturais, principalmente em regiões sócio-economicamente vulneráveis torna-se uma maneira de baixo custo para auxiliar o gerenciamento de setores de recursos hídricos e socioeconômicos locais, além do mais importante, prevenir a perda de vidas humanas.

Segundo Rockwood e Maddox (1988) um sistema de tempo que produz intensa precipitação, sempre está relacionado à atividade convectiva e é o resultado da interação de mecanismos físicos de diferentes escalas.

Essa interação de escalas temporais pode ser observada utilizando a Análise de Ondaleta e assim, pode-se descobrir a causa do ano/evento extremo, seja esse evento anomalamente positivo ou negativo.

Vários estudos sobre eventos extremos já utilizaram técnicas e metodologias distintas como em Moura e Kayano (1986), Rockwood e Maddox (1988), Easterling et al. (2000), Groisman et al. (2005), Brunetti, et al. (2006), Haylock et al. (2006), Santos e Brito (2007), Santos (2014), entre outros. Groisman et al. (2005), por exemplo, identificaram tendências positivas de aumentos sistemáticos de chuva e de extremos de chuva na região subtropical, no Sul e no Nordeste do Brasil.

Na meteorologia grande quantidade de trabalhos aplicaram a Análise de Ondaleta (AO) (Farge, 1992, Vitorino, 2003; Andreoli e Kayano, 2004; Schneider et al., 2005; Da Silva, 2009 e Da Silva et al., 2010 a e b). No que se refere à climatologia e à dinâmica atmosférica, alguns estudos também utilizaram a AO (Vitorino, 2003; Schneider et al., 2005; Da Silva et al., 2010). A grande maioria dos trabalhos desenvolvidos na dinâmica atmosférica enfocam as escalas climáticas, desde a sua variabilidade interdecadal à intrasazonal (Andreoli e Kayano, 2004; Da Silva, 2009; Alves et al., 2012; Da Silva et al., 2014). Em geral, estes trabalhos buscam uma metodologia eficaz na localização de fenômenos transientes e que atuem simultaneamente em várias escalas de tempo, proporcionando novas perspectivas e abordagens de análises, impossíveis de se efetuarem através dos métodos tradicionais (Gu e Philander, 1995; Torrence e Compo, 1998; Abreu Sá et al., 1998; Polzin e Hastenrath, 2014).
A AO é útil para detectar, analisar e caracterizar as escalas de tempo que afetam os sistemas atmosféricos. Esta ferramenta revela a estrutura temporal das séries temporais não-estacionárias. O reconhecimento que a $\mathrm{AO}$ possui propriedades matemáticas capazes de quantificar as relações tempo-escala em meteorologia estimula muitas pesquisas em mesoescala e na escala sinótica (Repelli et al., 1998; Schneider et al., 2005).

Dentre alguns tipos de ondaletas, a Morlet é complexa e possui características semelhantes às de sinais meteorológicos, tais como simetria ou assimetria, e variação temporal brusca ou suave (Weng e Lau, 1994; Morettin, 1999).

Alguns estudos, usando a Ondaleta Morlet, relacionam oscilações atmosféricas e climáticas aos sinais encontrados nas séries temporais, pois a partir de escalas temporais são identificados os sistemas ou fenômenos meteorológicos que os provocaram (Abreu Sá et al., 1995; Mann et al., 1995; Robok e Mao, 1995; Robock e Free, 1995; Trigo et al., 1995; Torrence e Webster, 1999; Andreoli e Kayano, 2004; Andreoli et al., 2004; Schneider et al., 2005; Knight et al., 2005; Da Silva et al., 2010; Polzin e Hastenrath, 2014). Projeções a partir da estatística AO podem ser vistas em Da Silva (2009), Da Silva et al. (2010), Kubota e Bonatti (2010), Khader et al. (2011), Alves et al. (2012), Da Silva (2013) e Polzin e Hastenrath (2014).

O presente artigo tem como objetivo identificar ciclos de extremos pluviométricos e de suas causas através das escalas temporais detectadas em séries de precipitação para as capitais do leste do Nordeste do Brasil.

\section{Material e Método}

\section{1. Área de estudo}

O Nordeste do Brasil (NEB) (Fig. 1) ocupa uma área de $1.561 .177,8 \mathrm{~km}^{2}$, equivalente a $18,3 \%$ do território nacional. A região Nordeste limita-se a leste e ao norte com o Oceano Atlântico, a oeste e sudoeste com os Estados do Pará, Tocantins e Goiás, e ao sul com os Estados de Minas Gerais e Espírito Santo.

A faixa costeira do Leste do Nordeste (ENE) se estende do Rio Grande do Norte ao sul da Bahia, também conhecida como Zona da Mata. O período mais chuvoso vai de abril a julho, com o pico de chuvas em maio (postos de Olinda e Salvador).

\subsection{Dados}

Os dados pluviométricos diários das capitais dos estados que compõem o leste do NEB foram obtidos através da Agência Nacional das Águas (ANA). Esses dados têm período em comum, de 1961-2014. O preenchimento dos dados faltosos ocorreu por correlação com outra estação 


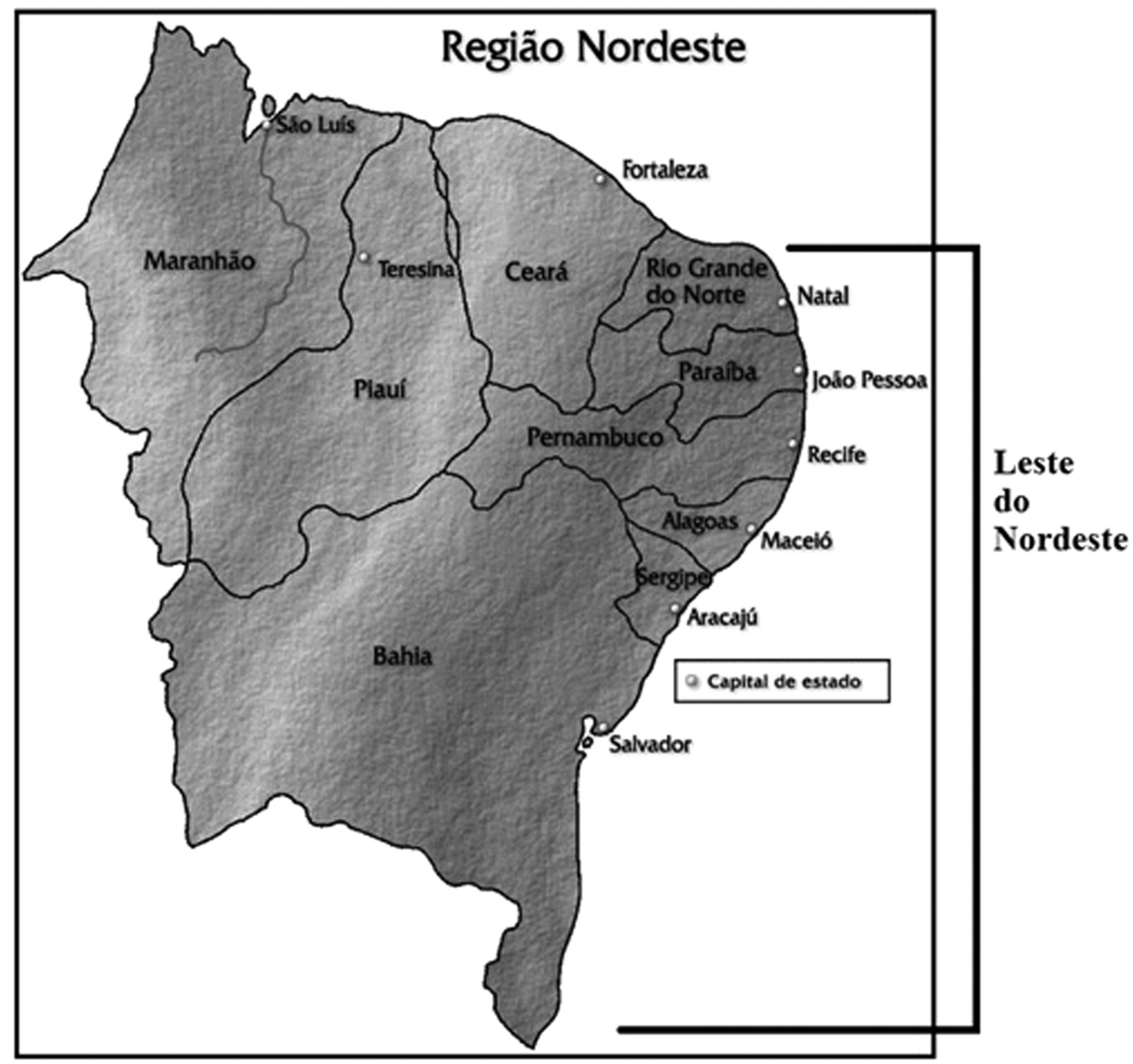

Figura 1 - Região Nordeste do Brasil com destaque para faixa leste do Nordeste.

meteorológica mais próxima e que apresentar melhor coeficiente de correlação.

Os dados foram adquiridos em formato de bloco de notas, convertidos para o Excel ${ }^{\circledR}$ e tratados para gerar o índice de Prp, o qual foi submetido à Análise de Ondaleta. Esse índice se refere à anomalia mensal de precipitação, normalizada pelo respectivo desvio-padrão mensal, calculado através de (Da Silva, 2009; Da Silva et al., 2010):

$$
A \operatorname{Var}_{i, j}=\left(\operatorname{Var}_{i, j}-\overline{\operatorname{Var}_{l}}\right) / \sigma_{i}
$$

em que $A V a r_{i, j}$ é a anomalia normalizada da precipitação no ano $j=1,2,3, \ldots, N$ e mês $i=1,2,3, \ldots, 12 ; \operatorname{Var}_{i, j}$ é a precipitação no ano $j=1,2,3, \ldots, N$ e mês $i=1,2,3, \ldots, 12$; $\overline{V a r_{l}}$ e $\sigma_{i}$ são a média climatológica e o desvio padrão do mês $i$.

O uso desse índice é justificado e utilizado por diversos autores (Kousky e Chu, 1978; Aceituno, 1988; An- dreoli et al., 2004; Da Silva, 2009; Da Silva et al., 2010; Da Silva, 2013).

\subsection{Análises de ondaletas}

Sua aplicabilidade na análise de sinais se deve principalmente porque permite decompor uma série temporal em diferentes níveis de resolução tempo-frequência e, então determinar, as componentes da variabilidade dominante (Torrence e Compo, 1998).

$\mathrm{O}$ termo ondaleta refere-se a um conjunto de funções com forma de pequenas ondas geradas por dilatações (a) e translações (b) de uma função simples $\psi(\mathrm{t})$ de variável real $\mathrm{t}$, algumas vezes chamada de ondaleta-mãe. As funções derivadas da ondaleta-mãe são denominadas ondaletas filhas, ou simplesmente onaeletas (Weng e Lau, 1994; Torrence e Compo, 1998). Esta função deve ser quadraticamente integrável dentro de um intervalo real, ou espaço $\left[L^{2}(\Re)\right]$, ou seja, deve apresentar energia finita. 
A ondaleta Morlet é complexa e possui características semelhantes às de sinais meteorológicos, tais como simetria ou assimetria, e variação temporal brusca ou suave. Segundo a literatura, este é um critério para escolha da função ondaleta (Weng e Lau, 1994; Morettin, 1999).

A ondaleta de Morlet é uma exponencial complexa modulada por uma Gaussiana (Andreoli et al., 2004) e é dada pela seguinte expressão:

$$
\psi(t)=e^{i \omega_{0} \eta} e^{-\eta^{2} / 2}
$$

em que $\eta=t / s$, onde $t$ é o tempo, $s$ é a escala da ondaleta em função do tempo $(=2 / \mathrm{d} t)$ e $\omega_{0}$ é uma frequência não-dimensional $\left(\operatorname{lag}_{1}=0,7\right)$, escolhidos conforme Andreoli et al. (2004); Todos introduzidos no "script" de programação do Software Matlab ${ }^{\circledR}$.

O período de anos dos ciclos e a escala temporal dominante foram obtidos por programação no Software Matlab ${ }^{\circledR}$ com comandos específicos.

Deve ainda ser lembrado que a AO depende do intervalo de tempo usado nas observações, ou seja, se os dados são totais ou médias mensais a $\mathrm{AO}$ não é capaz de informar variabilidade intramensal. Além disso, na análise climática a eficácia da ondaleta Morlet ainda não foi comprovada ser superior às de outras ondaletas, mesmo sendo muito utilizada pelos vários autores já citados no texto. Ainda é oportuno mencionar que $s$ - escala da ondeleta - não pode ser uma frequência superior ao intervalo de tempo das observações.

\section{Resultados e Discussão}

A Análise de Ondaleta tem a capacidade de detectar ciclos e escalas temporais em uma série de dados. Nas séries pluviométricas das capitais do leste do Nordeste foram identificadas escalas temporais, a escala temporal dominante em cada cidade e alguns ciclos que ocorreram em decorrência dessas escalas.

Em todas as capitais foram observados a atuação de fenômenos de tempo com frequência de 1 a 2 anos, possivelmente associados ao ciclo anual dos sistemas meteorológicos e oceânicos atuantes na região; também observou-se variabilidade da precipitação com frequência de 7 anos, provavelmente relacionadas com eventos ENOS e Dipólo do Atlântico (Clauzet e Wainer, 1999); de 11 anos, coincidente com o ciclo de Manchas solares (Kerr, 1996; Echer, 2003, Molion, 2005); entretanto, pode ser decorrente da variabilidade do Dipolo do Atlântico (Servain, 1991; Clauzet e Wainer, 1999). Ainda ocorreu a escala temporal de 20,2-22 anos, associada em alguns casos, à Oscilação Decadal do Pacífico (Mantua et al., 1997).

Ressalta-se que para obter um resultado mais contundente é necessário produzir ondaletas cruzadas, uma vez que, nem sempre os mínimos de manchas solares coincidem com os máximos de precipitação, nem todos os máxi- mos de manchas solares são coincidentes com os mínimos de precipitação.

Em todas as capitais estudadas foram identificados eventos extremos com índices de Prp anômalos relacionados às escalas temporais e ciclos dos fenômenos climáticos descritos anteriormente. Esses eventos ocorreram em sua maioria devido à ocorrência simultânea de várias escalas temporais como atestaram Rockwood e Maddox (1988) ou devido ocorrência dos fenômenos climáticos em mesma fase conforme Hastenrath e Heller (1977).

Os estudos de Markhann (1974), Hastenrath e Kaczmarczyk (1981), Chu (1984) e Andreoli et al. (2004) também observaram altos valores de precipitação em séries temporais decorrentes de união de escalas temporais distintas com ocorrência simultânea, o que também pode ser a causa de anos com anomalias pluviométricas encontrados aqui.

A forte influência do Oceano Atlântico e de seu Dipolo esteve presente em todas as séries de Prp de todas cidades estudadas; a partir da detecção unânime da escala temporal de 11 anos vista nas seis (6) séries pluviométricas, sendo escala dominante ou secundária, em sua maioria. Essa clara relação entre as precipitações do leste do Nordeste e o sinal do Dipolo do Atlântico foi também relatada em Souza et al. (1998).

Somente a primeira Figura das AO terão linhas coloridas sobre a imagem no intuito deixar mais fácil a visualização de escalas temporais e ciclos. As demais seguem a mesma interpretação.

Na série de Maceió a escala de 20,2 anos não ocorreu e sim, a escala de 22 anos. Todas as outras capitais apresentaram a escala de 20,2-22 anos e seus ciclos.

Em Polzin e Hastenrath (2014) foram identificadas as escalas preferenciais de 13,2; 9,9 e 5,6 anos na série pluviométrica de Fortaleza (CE), situada no Norte da região Nordeste. Corroborando com esses resultados, neste trabalho, para o leste do Nordeste, foram encontradas escalas temporais próximas a essas, sendo 13,1; 9,2 e 5,5 anos.

\subsection{Salvador}

Em Salvador, os principais extremos de precipitação (Fig. 2a) são observados nos índices de Prp em 1964, 1977/78, 1984, 1994, 2000, 2010/11. Esses anos fazem parte de ciclos de fenômenos climáticos como ENOS, Dipólo do Atlântico, Ciclo de manchas solares e Oscilação Decadal do Pacífico. O extremo pluviométrico de 1964, por exemplo, ocorreu devido junção de várias escalas temporais (sazonal + interanual curta $+1-2$ anos +7 anos +22 anos) (Fig. 2b), potencializando os totais pluviométricos locais, como também sugeriram Hastenrath e Heller (1977) e Rockwood e Maddox (1988). Os outros extremos (1977/78, 1984, 1994, 2000, 2010/11) também são causados pela união das escalas temporais de diferentes períodos 


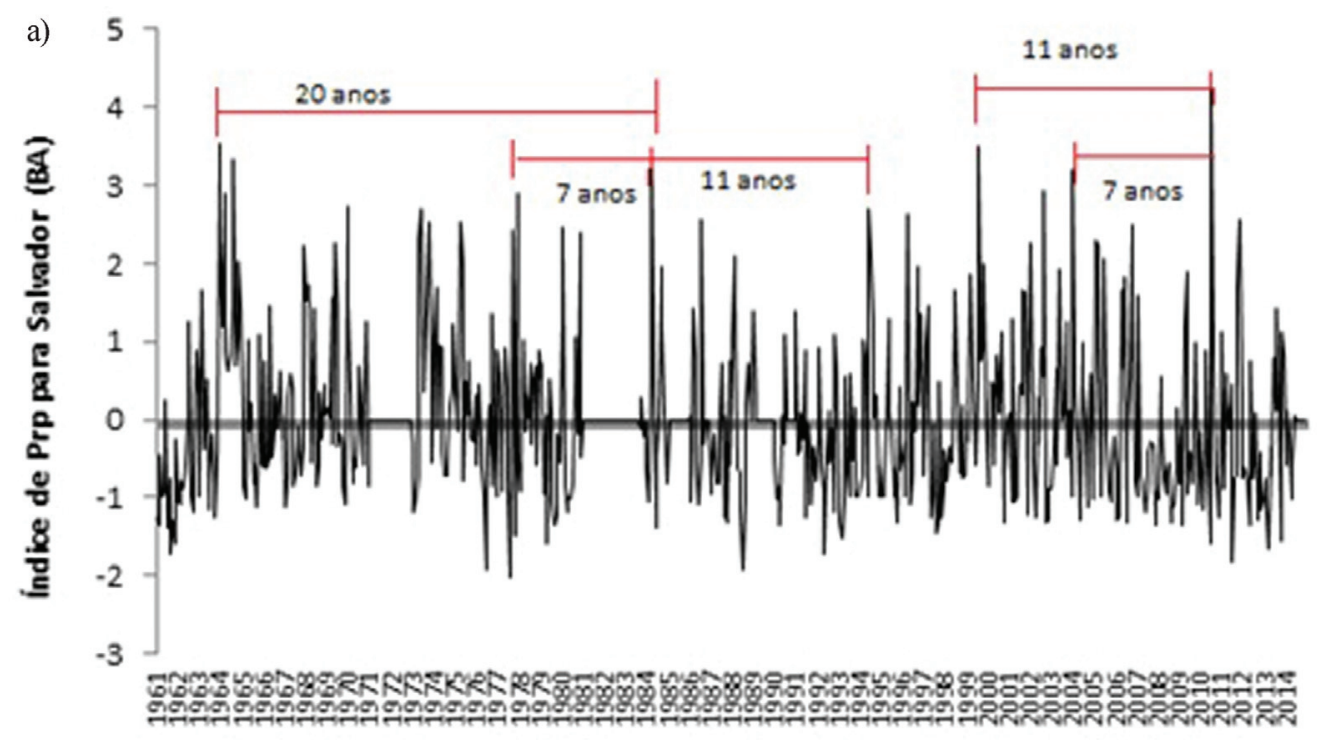

anos

b)

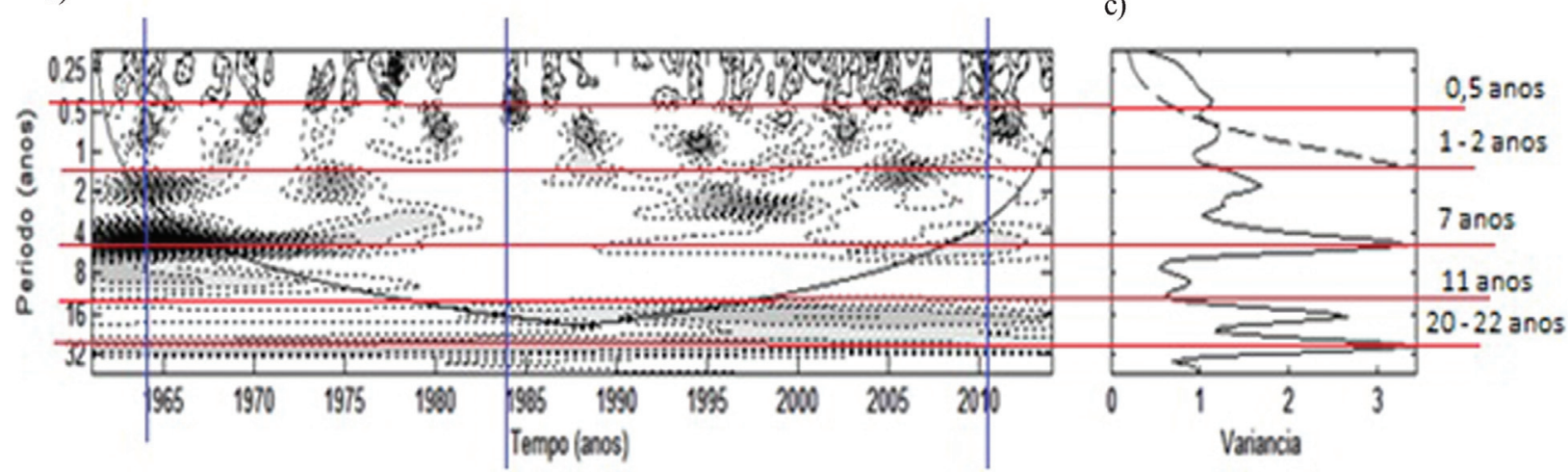

Figura 2 - a) Índice de precipitação (Prp) para Salvador (BA) normalizado pelo desvio padrão; b) Espectro de potência de ondaleta (EPO) para Prp. Contornos sombreados correspondem a variâncias normalizadas significativas ao nível de $5 \%$. A curva em forma de U representa o cone de influência, sob a qual o efeito de borda é importante; c) Espectro de potência global (EPG), com o contorno tracejado indicando que o EPG é significativo ao nível de confiança de $95 \%$.

(Figs. 2a e 2b) como também encontraram Markhann (1974) e Hastenrath e Kaczmarczyk (1981).

No que se referem aos ciclos, os anos de 1964 e 1984 fazem parte do ciclo de aproximadamente 20 anos associado à Oscilação Decadal do Pacífico (Mantua et al., 1997). Essa escala temporal (decadal) é a escala dominante e persistente como observado nas Fig. 2b e 2c.

Ciclos de 11 anos foram identificados entre $1984 \mathrm{e}$ 1995; e de 2000 a 2011 (Fig. 2a). Esses ciclos são ligados ao ciclo de Manchas solares (Kerr, 1996; Echer, 2003; Molion, 2005) e ao Dipólo do Atlântico (Clauzet e Wainer, 1999). A escala dominante secundária de 11 anos está presente ao longo do EPO (Fig. 2b) desde 1981. A partir desse ano também percebe-se maior ocorrência de extremos de Prp, como também observado por Groisman et al. (2005) e Santos e Brito (2007).
Ciclos de 7 anos ocorreram de 1977/84 e de 2004/2011-2012 em decorrência da escala temporal de 7 anos ligada ao sinal persistente do ENOS e ligada também ao Dipólo do Atlântico (Clauzet e Wainer, 1999).

As escalas sazonal, interanual curta, interanual, de 1-2 anos também são visualizadas no índice de Prp (Fig. 2a).

\subsection{Aracaju}

Os primeiros anos da série de Prp para Aracaju foram marcados pelos maiores índices positivos (Fig. 3a), indicando que nesse período houveram alguns anos anomalamente chuvosos. No EPO (Fig. 3b) pode observar a causa disso. A ocorrência simultânea ou junção de fenômenos de escalas temporais distintas (Rockwood e Maddox, 1988; Hastenrath e Heller, 1977; Markhann, 1974; Chu, 1984; 


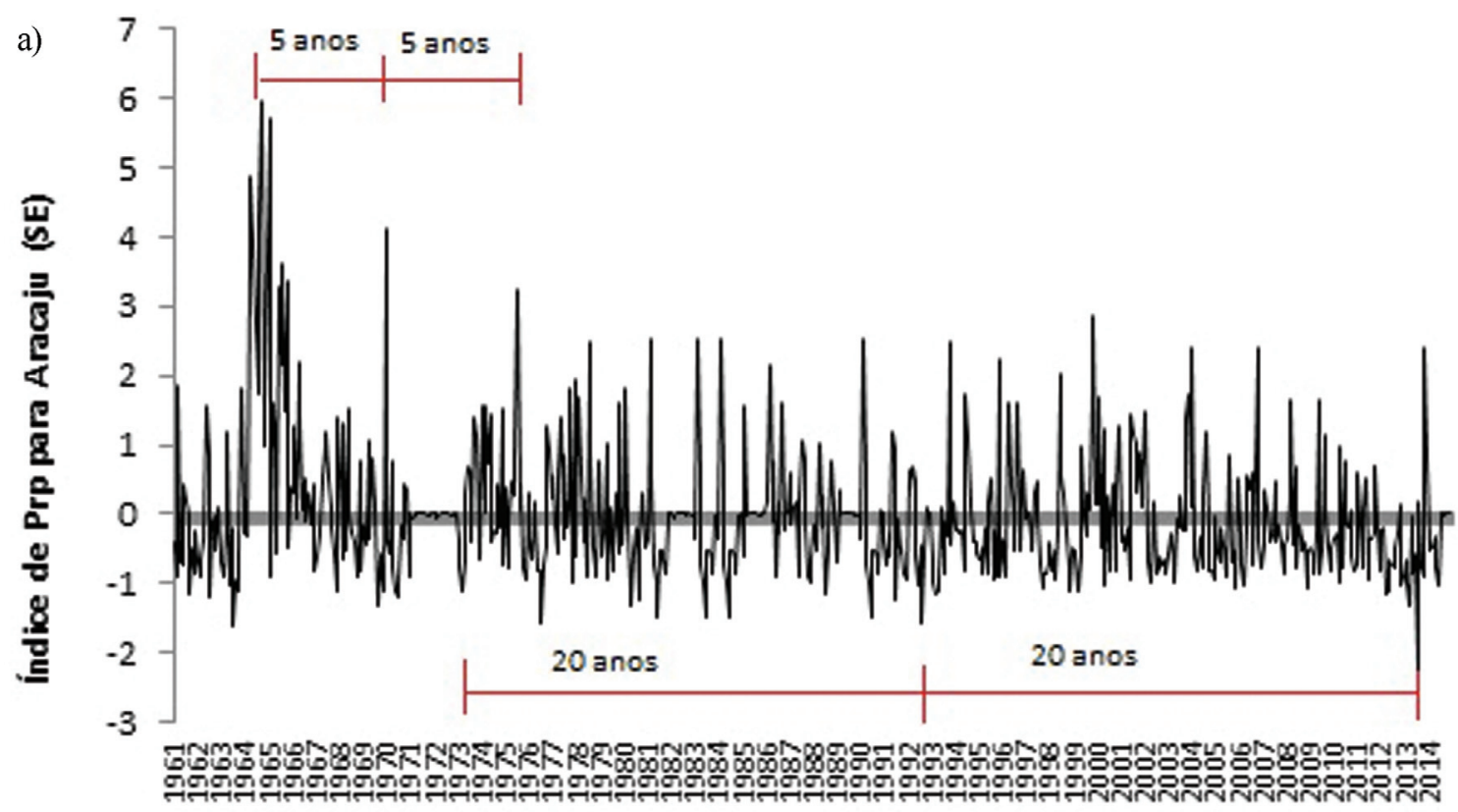

anos

b)

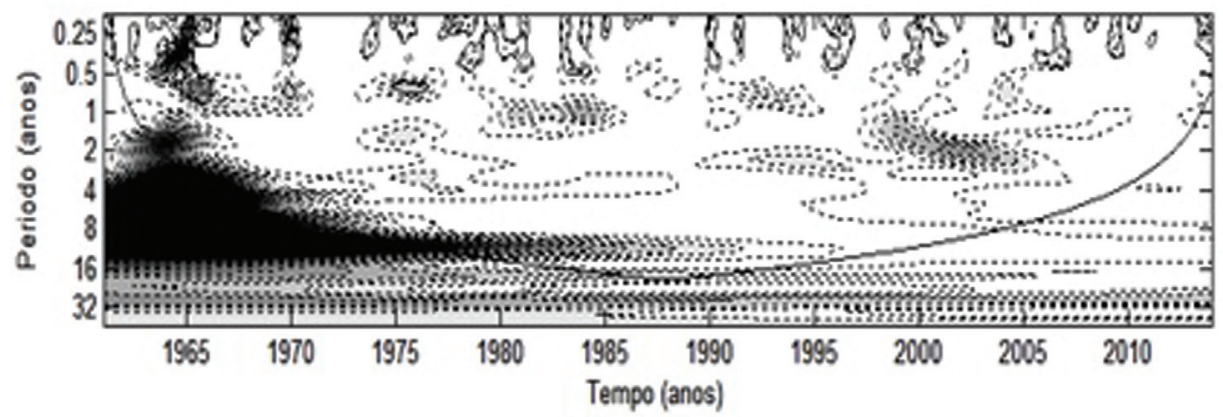

c)

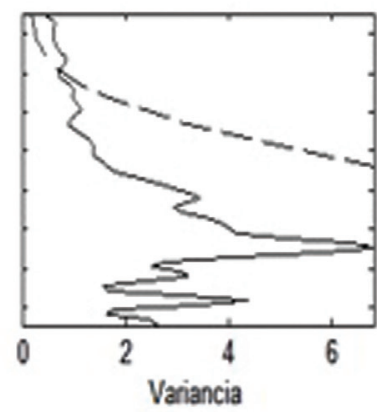

Figura 3 - a) Índice de precipitação (Prp) para Aracaju (SE) normalizado pelo desvio padrão; b) Espectro de potência de ondaleta (EPO) para Prp. Contornos sombreados correspondem a variâncias normalizadas significativas ao nível de 5\%. A curva em forma de U representa o cone de influência, sob a qual o efeito de borda é importante; c) Espectro de potência global (EPG), com o contorno tracejado indicando que o EPG é significativo ao nível de confiança de $95 \%$.

Hastenrath e Kaczmarczyk, 1981) ocasionaram esses incrementos na precipitação e nos valores de Prp.

Essa junção deu-se entre as escalas sazonal, interanual, entre 1-2 anos, de 7 anos também ligada ao ENOS, escala de 11 anos (dominante) e a escala de 20,2-22 anos (Figs. 3b e 3c).

Nesses mesmos anos iniciais citados foram detectados ciclos com período de ocorrência de 5 anos, valor próximo ao observado por Polzin e Hastenrath (2014) como sendo uma das escalas preferenciais no Norte do Nordeste.

Valores de Prp negativos também ocorreram e com ciclos de 20 anos (Fig. 3a). O ano de 2013, por exemplo, menor valor de Prp para Aracaju, não apresentou nenhuma junção de escalas temporais nem fenômeno fortemente atuante, somente resquícios da escala decadal. Essa ausência pode ser o motivo de anos com baixos valores de Prp.

\subsection{Maceió}

Em Maceió a escala dominante encontrada foi de 11 anos (Figs. 4b e 4c), mostrando relação direta entre a precipitação local e o Dipolo do Atlântico conforme Servain (1991), Souza et al. (1998) e Clauzet e Wainer (1999). Deve ser lembrado que a mesma escala tem relação com ciclo de Manchas solares (Kerr, 1996; Echer, 2003; Molion, 2005).

Essa escala temporal atuou principalmente entre 1964 e 2002 (Fig. 4b) e justamente nesse período foram observados os picos de máximos valores positivos de Prp (Fig. 5a) como em 1964, 1970, 1977, 1989, 1995, 2001 e 2002. 


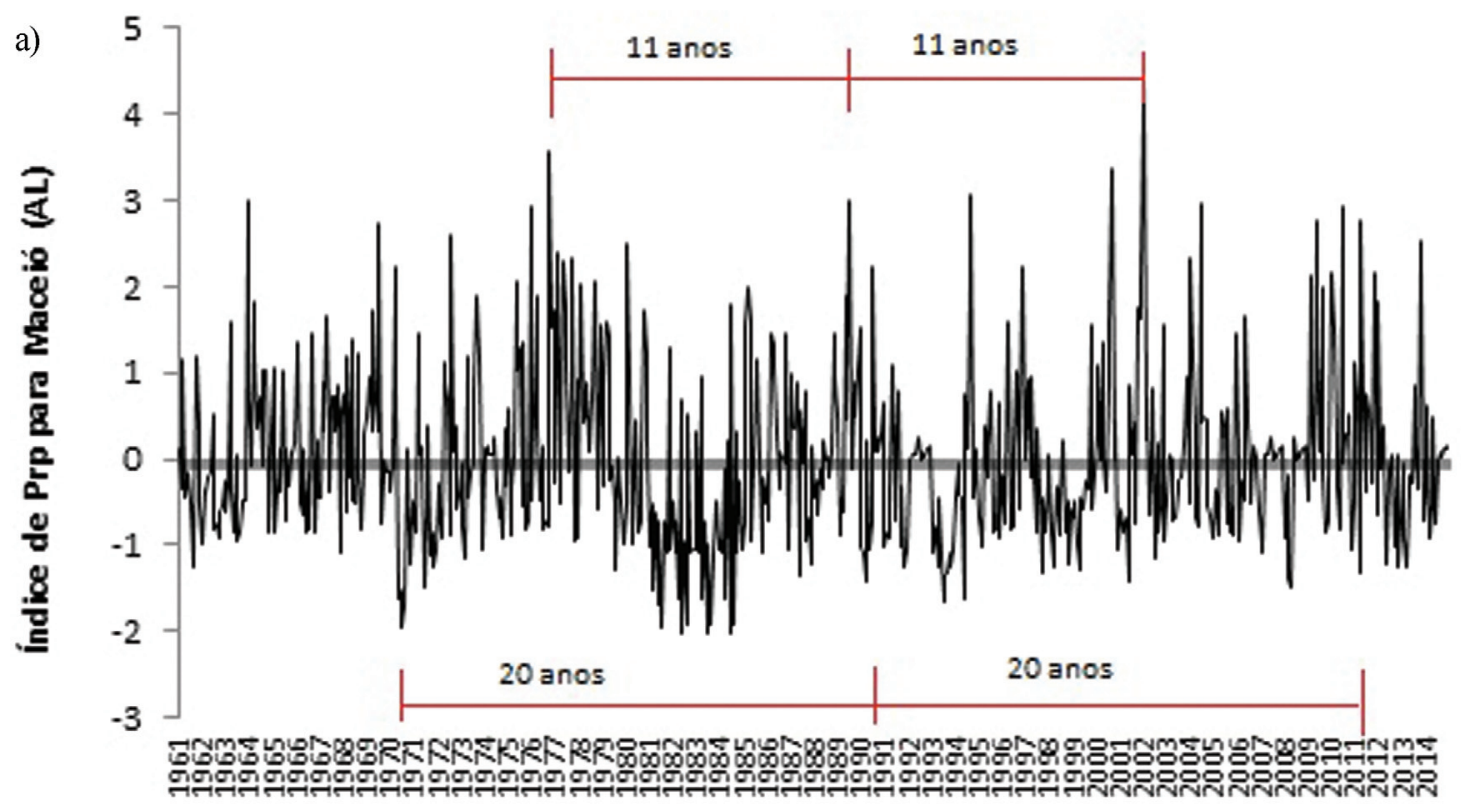

b)

anos

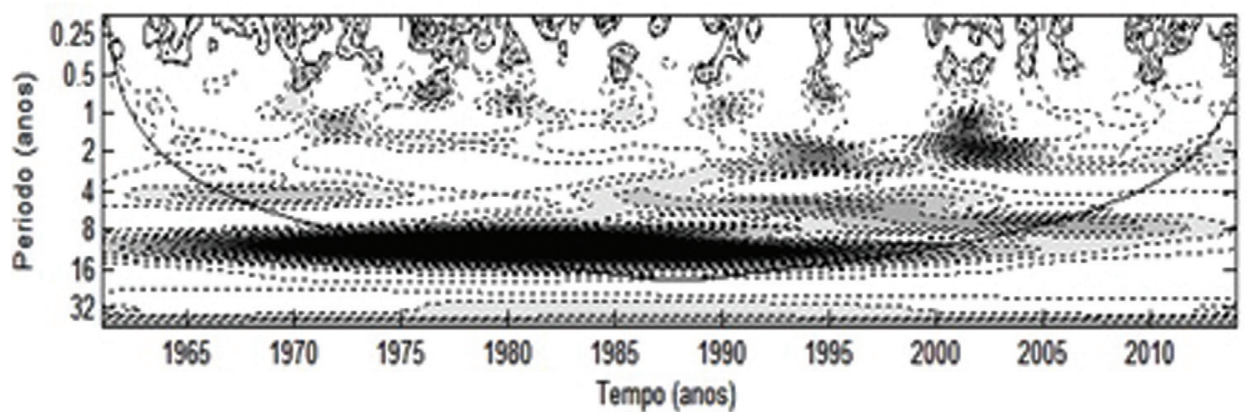

c)

Figura 4 - a) Índice de precipitação (Prp) para Maceió (AL) normalizado pelo desvio padrão; b) Espectro de potência de ondaleta (EPO) para Prp. Contornos sombreados correspondem a variâncias normalizadas significativas ao nível de 5\%. A curva em forma de U representa o cone de influência, sob a qual o efeito de borda é importante; c) Espectro de potência global (EPG), com o contorno tracejado indicando que o EPG é significativo ao nível de confiança de $95 \%$.

A escala decadal secundária (Fig. 4c) vista com menor significância está presente ao longo da série e seus ciclos ocasionaram baixos valores de Prp como em 1971, 1991 e 2011 (Fig. 4a).

\subsection{Recife}

A escala decadal de 11 anos é a dominante na série de Prp em Recife (Fig. 5b), mas sem significância estatística (Fig. 5c). Os ciclos relacionados com essa escala foram encontrados ao longo dos anos como na Figura 5a. Extremos de precipitação, Prp, em decorrência da escala de 11 anos ocorreram em 1971, 1982, 1993, 2001 e 2012. Autores associam-a ao ciclo de manchas solares e ao Dipolo do Atlântico (Servain, 1991; Kerr, 1996; Clauzet e Wainer, 1999; Echer, 2003; Molion, 2005).

A escala de 7 anos esteve presente ao longo de toda série no EPO, sendo também uma influenciadora sobre as precipitações locais, principalmente entre 1961 a 1975, de 1990 a 2004 e de 2007 a 2014 (Fig. 5b).

As escalas temporais interanual de 1-2 anos, interanual curta e sazonal também ocorreram nessa série (Figs. $5 \mathrm{~b}$ e 5 c). A escala sazonal obteve significância estatística. Já a união de todas as escalas temporais que ocorreram simultaneamente promoveram os altos valores de Prp (anos de precipitação extrema, positivamente) em 1971 e 2001, atestando as hipóteses de autores como Markhann (1974), Hastenrath e Kaczzmarczyk (1981), Chu (1984), Rockwood e Maddox (1988), Andreoli et al. (2004) e Da Silva (2009).

\subsection{João Pessoa}

A cidade de João Pessoa teve a escala temporal dominante de 11 anos presente em toda série e em grande parte, atuando em conjunto/simultaneamente com a escala tem- 


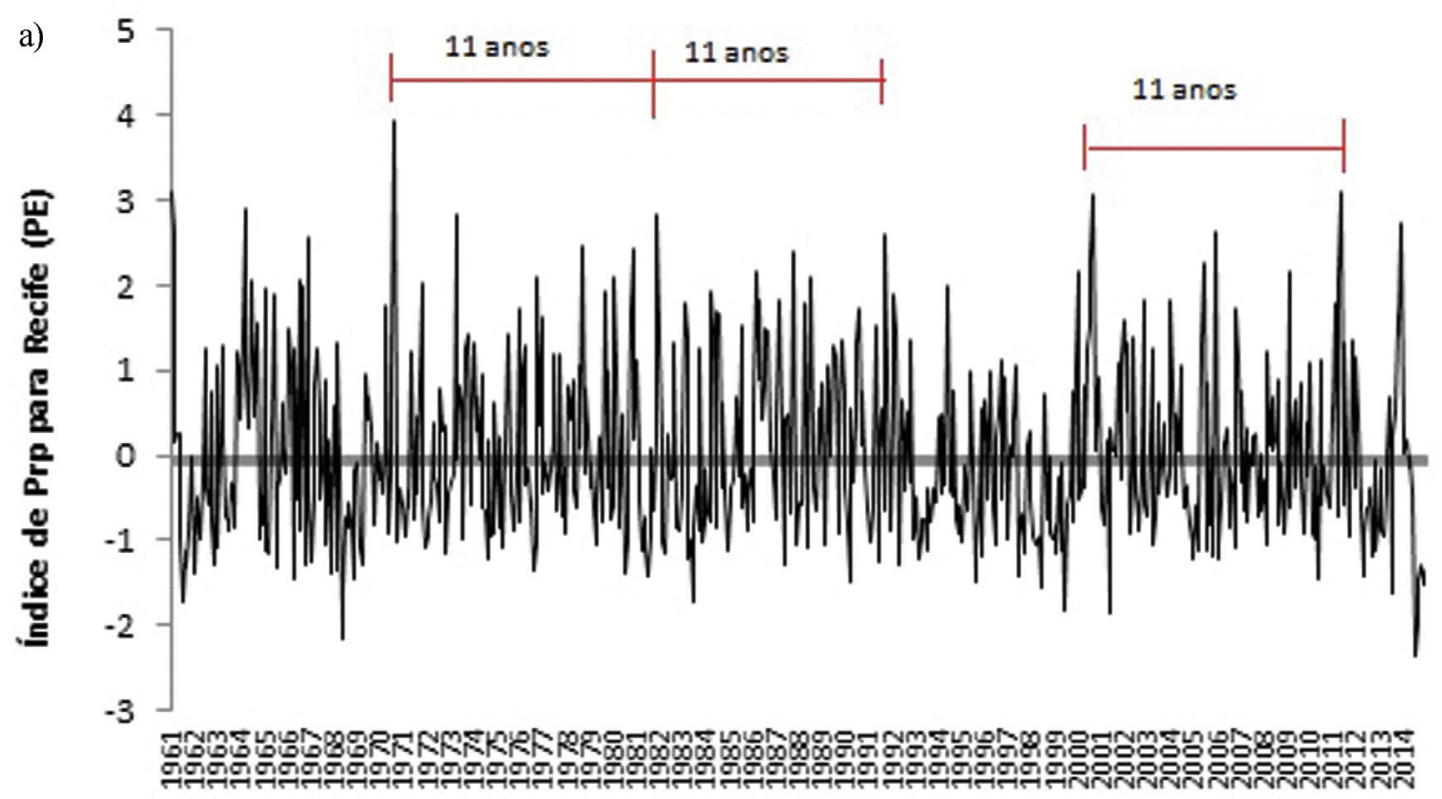

b)

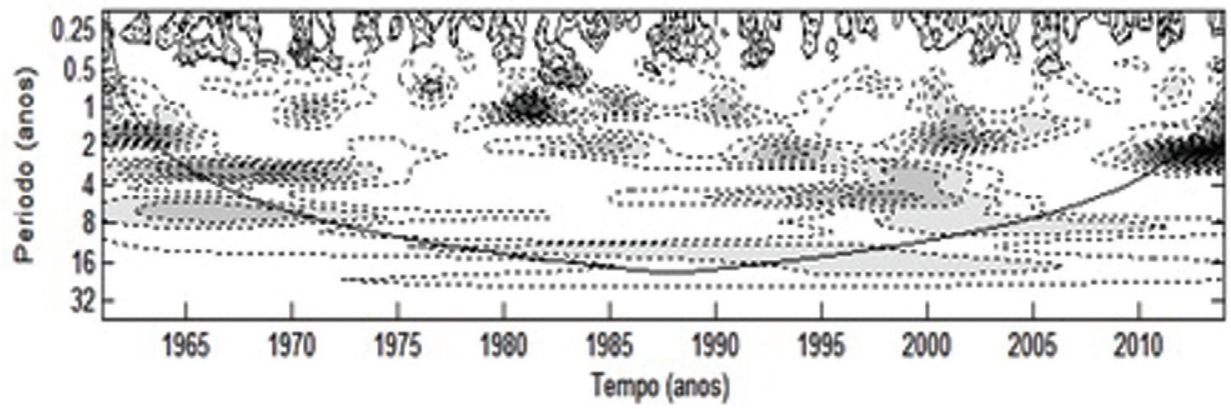

c)

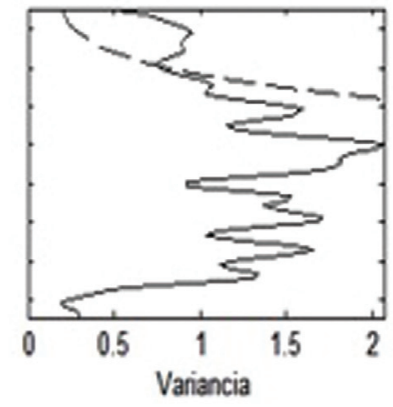

Figura 5 - a) Índice de Precipitação (Prp) para Recife (PE) normalizado pelo desvio padrão; b) Espectro de potência de ondaleta (EPO) para Prp. Contornos sombreados correspondem a variâncias normalizadas significativas ao nível de $5 \%$. A curva em forma de U representa o cone de influência, sob a qual o efeito de borda é importante; c) Espectro de potência global (EPG), com o contorno tracejado indicando que o EPG é significativo ao nível de confiança de $95 \%$.

poral de 7 anos (Figs. 6b e 6c). Estas foram as escalas dominante e secundária, respectivamente. A escala de 11 anos origina ciclos de aproximadamente 10 anos que são facilmente visualizados na série de Prp (Fig. 6a), tendo como exemplos, 1969-1979 e 1979-1989. Nesse mesmo período ocorreram concomitantemente as duas escalas já citadas (Fig. 6b), gerando também os extremos e máximos valores de Prp. Já os baixos valores em 1972 e 1982 (Fig. 6a) tem relação com a ocorrência de uma das fases dos fenômenos com escala sazonal e interanual de 1-2 anos (Fig. 6b).

\subsection{Natal}

Já para a série de Prp de Natal, a escala temporal dominante foi de 22 anos, atuante desde 1961 até 2014 (Fig. 7b). A escala secundária de 11 anos influenciou também a série de Prp. Ambas resultaram em ciclos de 11 e
22 anos (consequência do ciclo de 11 anos) observados no Prp (Fig. 7a). Além das influências do Dipolo do Atlântico, Manchas solares e ODP observadas anteriormente, a junção da ocorrência simultânea de escalas temporais distintas também explicam os altos valores de Prp para Natal (Fig. 7a). Os eventos/anos extremos mais importantes em Natal ocorreram em 1961, 1972, 1987, 1998, 2004 e 2008/2009.

\section{Conclusões e Recomendações}

Anos com eventos/precipitações extremas foram identificados e as Análises de Ondaletas sugeriram suas causas climáticas (sazonalidade, variabilidade interanual, ENOS, Dipolo do Atlântico, Manchas Solares e Oscilação Decadal do Pacífico).

As escalas temporais de 7,7;11; 22 anos (entre outras) foram detectadas em todas capitais, podendo ter relação do Leste do NEB com ciclos do ENOS, Dipolo do O. 


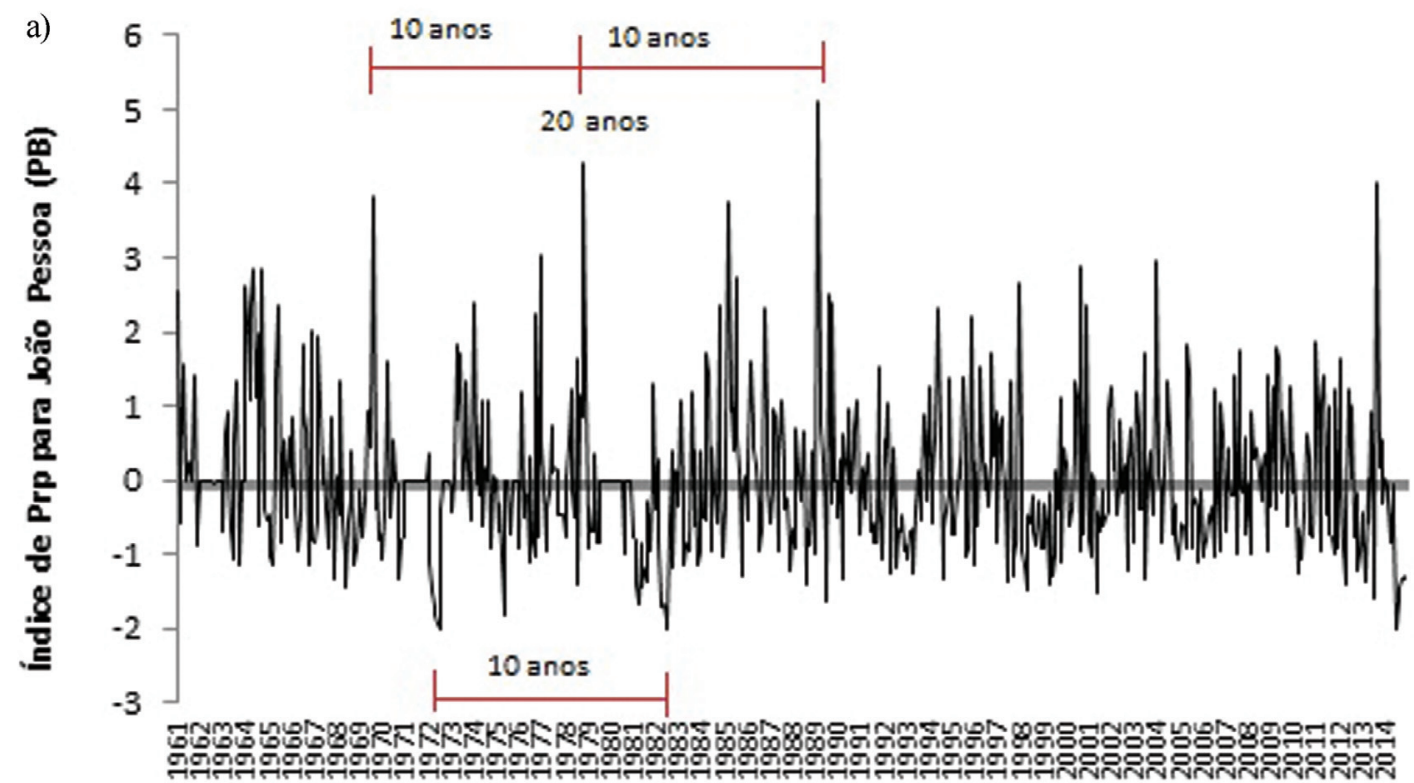

b)

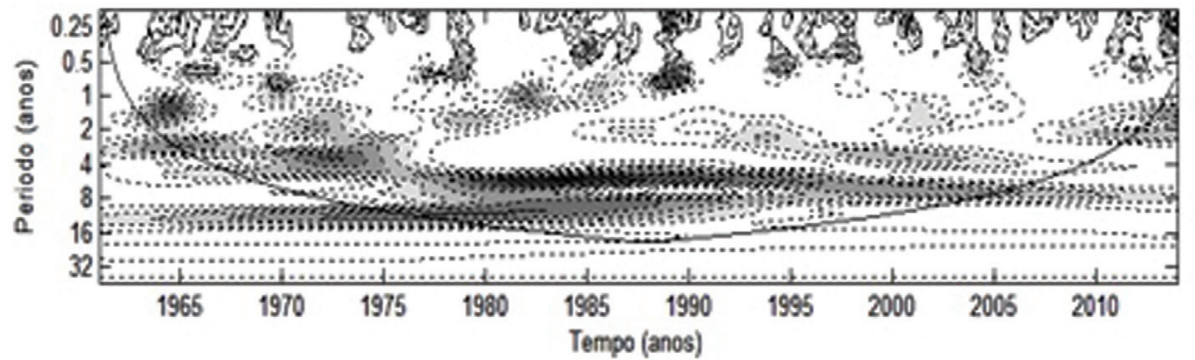

c)

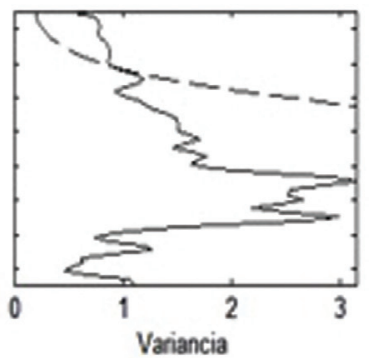

Figura 6 - a) Índice de Precipitação (Prp) para João Pessoa (PB) normalizado pelo desvio padrão; b) Espectro de potência de ondaleta (EPO) para Prp. Contornos sombreados correspondem a variâncias normalizadas significativas ao nível de $5 \%$. A curva em forma de U representa o cone de influência, sob a qual o efeito de borda é importante; c) Espectro de potência global (EPG), com o contorno tracejado indicando que o EPG é significativo ao nível de confiança de $95 \%$.

Atlântico e Ciclo de Manchas Solares, sendo a mesmas mais contundente através de ondaletas cruzadas, uma vez que, nem sempre os mínimos de manchas solares coincidem com os máximos de precipitação, nem todos os máximos de manchas solares são coincidentes com os mínimos de precipitação. Assim, sugere-se para outros trabalhos, ou trabalhos futuros, que sejam produzidas ondaletas cruzadas, ou seja, ondaletas com dados de entrada dos índices de anomalia normalizada de precipitação e de manchas solares, bem como dos índices precipitação e anomalias de TSM do dipolo.

Em todas as capitais estudadas foram também identificados eventos extremos com índices de Prp anômalos relacionados às escalas temporais e ciclos dos fenômenos climáticos descritos anteriormente. Esses eventos ocorreram em sua maioria devido à ocorrência simultânea de várias escalas temporais ou devido ocorrência dos fenômenos climáticos em mesma fase. Também foram observados altos valores de precipitação nas séries temporais decorrentes de união de escalas temporais distintas com ocorrência simultânea.

A forte influência do Oceano Atlântico e de seu Dipolo esteve presente em todas as séries de Prp de todas cidades estudadas. Houve detecção unânime da escala temporal de 11 anos vista nas séries pluviométricas, sendo escala dominante ou secundária, em sua maioria, evidenciando a relação entre as precipitações do leste do Nordeste e o sinal do Dipolo do Atlântico.

Para o leste do Nordeste foram encontradas as escalas preferenciais de 13,1; 9,2 e 5,5 anos, bem próximos aos valores encontrados para o Norte do Nordeste.

Com o acompanhamento desses fenômenos/sistemas climáticos pode-se monitorar a pluviometria local e prever climatologicamente os anos de possíveis eventos extremos, além de conhecer suas possíveis causas. 


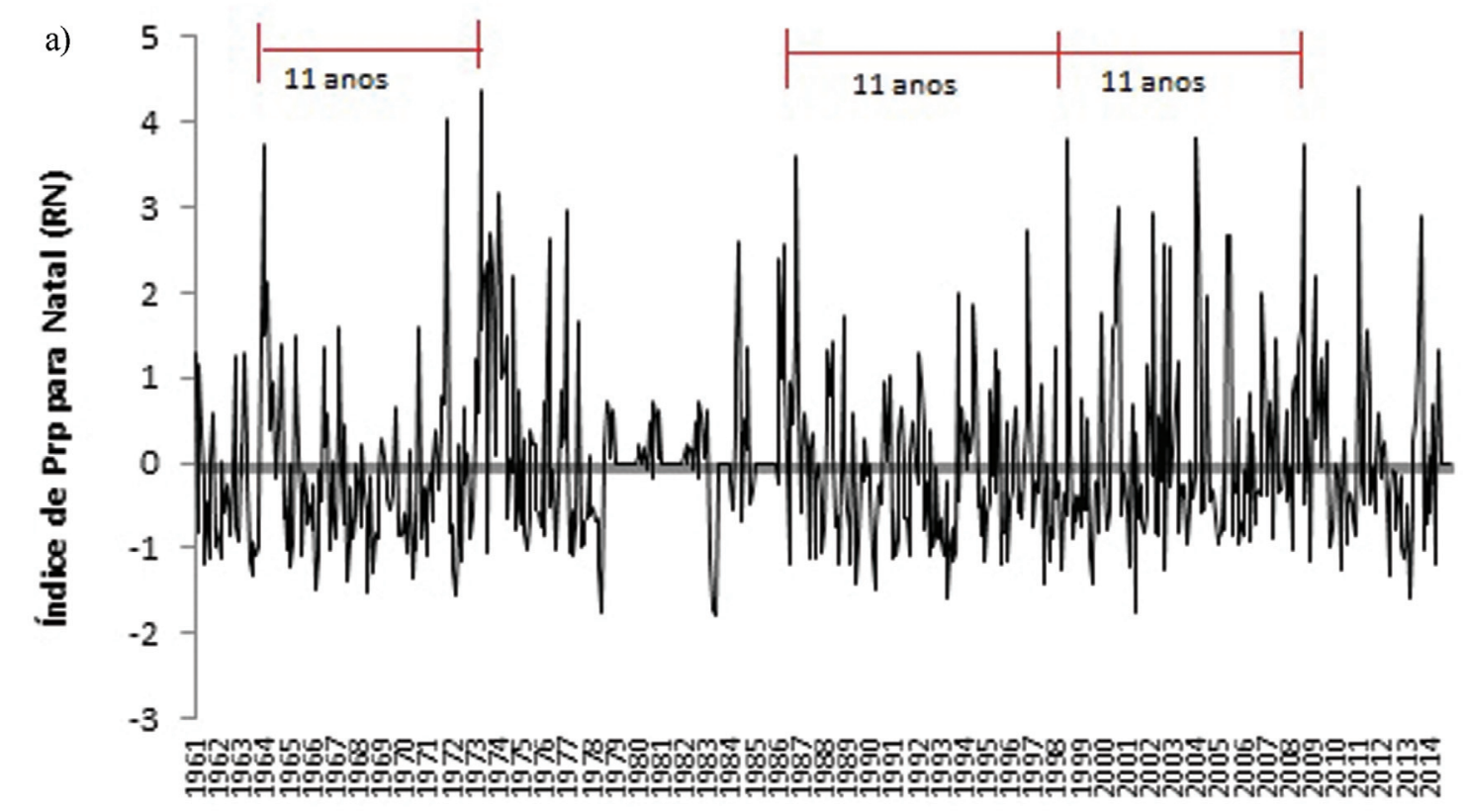

b)

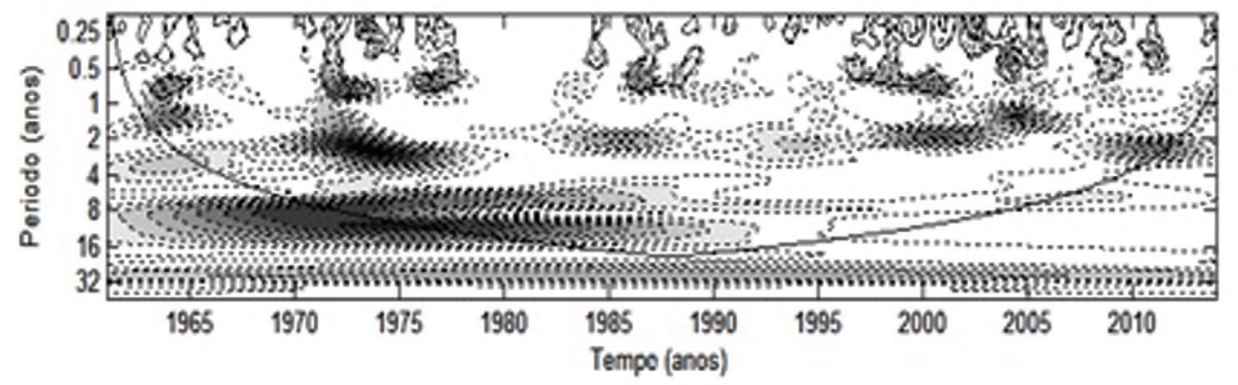

c)

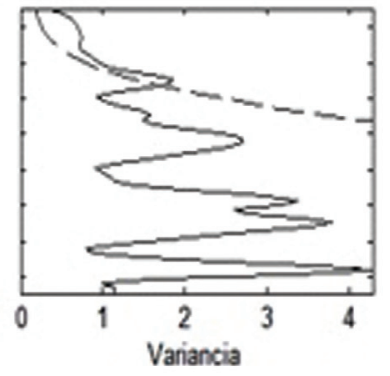

Figura 7 - a) Índice de Precipitação (Prp) para Natal (RN) normalizado pelo desvio padrão; b) Espectro de potência de ondaleta (EPO) para Prp. Contornos sombreados correspondem a variâncias normalizadas significativas ao nível de $5 \%$. A curva em forma de U representa o cone de influência, sob a qual o efeito de borda é importante; c) Espectro de potência global (EPG), com o contorno tracejado indicando que o EPG é significativo ao nível de confiança de $95 \%$.

\section{Agradecimentos}

A autora agradece ao CNPq pela concessão de recursos oriundos do Edital Universal 2014, os quais possibilitaram a realização dessa pesquisa.

\section{Referências}

ABREU SÁ, L.D.; SAMBATTI, S.B.M.; GALVÃO, G.P. Ondeleta de morlet aplicada ao estudo da variabilidade do nível do rio Paraguai em Ladário, MS; Número Especial, Pesquisa Agropecuária Brasileira, Brasília, v.33, p. 1775-1785, 1998.

ACEITUNO, P. On the functioning of the southern oscillation in the South American sector. Part 1: surface climate, Monthly Weather Review, v. 116, p. 505-524, 1988.

ALVES, J.M.B.; SOUZA, E.B.; COSTA, A.A.; MARTINS, E.S.P.R.; SILVA, E. M. Sobre o sinal de um downscaling dinâmico às oscilações intrassazonais de precipitação no setor norte do nordeste do Brasil. Revista Brasileira de Meteorologia, v. 27, n. 2, 219-228, 2012.

ANDJELKOVIC, I. Guidelines on non-structural measures in urban measures in urban flood management. Paris: UNESCO, 87 p., 2001.

ANDREOLI, R.V.; KAYANO, M.T. Multi-scale variability of the sea surface temperature in the Tropical Atlantic, Journal of Geophysical Research, 109, C05009, 2004.

ANDREOLI, R.V.; KAYANO, M.T.; GUEDES, R.L.; OYAMA, M.D.; ALVES, M.A.S. A influência da temperatura da superfície do mar dos Oceanos Pacífico e Atlântico na variabilidade de precipitação em Fortaleza, Revista Brasileira de Meteorologia, v. 19, n. 3, p. 337-344, 2004.

CLAUZET, G.; WAINER, I. Identificação da variabilidade de baixa frequência em algumas regiões da costa sudeste-nordeste do Brasil. Revista Brasileira Oceanografia, v. 47, n. 1, p. 69-78, 1999.

BRUNETTI, M.; MAUGERI, M.; MONTI, F.; NANNI, T. Temperature and precipitation variability in Italy in the last two 
centuries from homogenized instrumental time series. International Journal of Climatology, v. 26, p. 345-381, 2006.

CHU, P.S. Time and space variability of rainfall and surface circulation in the northeast Brazil -tropical atlantic sector. Journal of the Meteorological Society of Japan, v. 26, n. 2, p. 363-369, 1984.

DA SILVA, D.F. Análise de aspectos climatológicos, agroeconômicos, ambientais e de seus efeitos sobre a bacia hidrográfica do rio Mundaú (AL E PE), março de 2009, 212 p., Tese de Doutorado em Recursos Naturais, UFCG, Campina Grande (PB), 2009.

DA SILVA, D.F.; Kayano, M.T.; SOUSA, F. de A.S. Uso de ferramentas estatísticas para acompanhamento climático e prevenção de riscos na bacia hidrográfica do rio Mundaú (Brasil). Revista Territorium (Portugal), v. 17, p. 17-26, 2010a.

DA SILVA, D.F.; SOUSA, F. DE A.S. DE; KAYANO, M.T. Escalas temporais da variabilidade pluviométrica na bacia hidrográfica do rio mundaú. Revista Brasileira de Meteorologia, v. 25, p. 147-155, 2010b.

DA SILVA, D.F. Aplicação das análises de Ondeletas para previsão climática e na prevenção de risco climático no Estado do Ceará. In: Luciano Lourenço e Manuel Mateus. (Org.). Riscos naturais, antrópicos e mistos: Homenagem ao Prof. Dr. Fernando Rebelo. $1^{\text {a }}$ Ed. Coimbra-Portugal: Universidade de Coimbra, v. 1, p. 235-250, 2013.

DA SILVA, D.F.; COSTA, I.M.; MATEUS, A.E. Escalas temporais e tendências observadas nas temperaturas máximas no Estado do Ceará. Revista Ambiência. Guarapuava (PR) v. 10 n. 2 p. $465-487,2014$

EASTERLING, D.R.; EVANS, J.L.; GROISMAN, P.Y.; KARL, T.R.; KUNKEL, K.E.; AMBENJE, P. Observed variability and trends in extreme climate events. Bulletin of American Meteorological Society, v. 81, p. 417-425, 2000.

ECHER, E.; RIGOZO, N.R.; NORDEMANN, D.J.R.; VIEIRA, L.E.A.; PRESTES, A.; FARIA, H.H. O número de manchas solares, índice da atividade do sol. Revista Brasileira de Ensino de Física, São Paulo, v. 25, n. 2, 2003.

FARGE, M. Wavelet transforms and their applications to turbulence. Annual Review of Fluid Mechanics, v. 24, p. 395 457, 1992.

FERREIRA, N.J.; CHAN, C.S.; SATYAMURTI, P. Análise dos distúrbios ondulatórios de leste sobre o Oceano Atlântico Equatorial Sul. In: Anais ... VI Congresso Brasileiro de Meteorologia, Salvador, p. 462-468, 1990.

GROISSMAN, P. et al. Trends in intense precipitation in the climate record. Journal of Climate, n. 18, p. 1326-50, 2005.

GU, D.; PHILANDER, S.G.H. Secular changes of annual and interannual variability in the tropics during the past century, Journal of Climate, v. 8, n. 4, p. 864-876, 1995.

HASTENRATH, S.; HELLER, L. Dynamics of climatic hazards in northeast Brazil. Quarterly, Journal of the Royal Meteorological Society, n. 103, v. 435, p. 77-92, 1977.

HASTENRATH, S.; KACZMARCZYK, E.B. On spectra and coherence of tropical climate anomalies. Tellus, v. 33, n. 5, p. 453-462, 1981.

HAYLOCK, M.R.; PETERSON, T.C.; ALVES, L.M.; AMBRIZZI, T.; ANUNCIAÇÃO, Y.M.T.; BAEZ, J.; BARROS, V.R.; BERLATO, M.A.; BIDEGAIN, M.; CORONEL, G., et al. Trends in total and extreme South Ameri- can rainfall 1960-2000 and links with sea surface temperature. Journal of Climate, v. 19, p. 1490-1512, 2006.

IPCC- Intergovernmental Panel on Climate Change, 2007. Climate Change 2007 - The Physical Science Basis. Contribution of working group I to the fourth assessment report of the IPCC. Cambridge University Press, Cambridge, 2007.

IPCC - Intergovernmental Panel on Climate Change. 2010. Clean Development Mechanism, Emission factor for the Brazilian South-Southeast-Midwest interconnected grid. Acesso em 03-12-2014. Disponível em: http://cdm.unfecc.int/.

IPCC - Intergovernamental Panel on Climate Change. 2014. Working Group III - Mitigation of Climate Change. Chapter 8: Tranport. Acesso em 03/12/2014. Disponível em: http://report.mitigation2014.org/drafts/final-draft-postplenary/ipcc_wg3_ar5_finaldraft_postplenary_chapter8.pdf

ISDR - International Strategy for Disaster reduction. Living with risk: a global review of disaster reduction initiatives. Preliminary version. Geneva, Switzerland: UN/ISDR, 2002.

KERR, R.A. A now dawn for sun-climate links? Science, v. 271, n. 5254, p. 1360-1361, 1996.

Khader, C.A.M.; abreu sá, L.D.; moraes, O.; silva, r.; arbage, M.C.A. Análise de ondeletas aplicada ao estudo de fenômenos da camada limite noturna acima de uma lavoura de arroz. Anais ...VII Workshop Brasileiro de Micrometeorologia, 2011.

KNIGHT, J.R.; ALLAN, R.J.; FOLLAND, C.K.; VELLINGA, M.; MANN, M.E. A signature of persistent natural thermohaline circulation cycles in observed climate. Geophysical Reserarch Letters, v. 32, L20708, 2005.

KUBOTA, P. Y.; BONATTI, J.P. Variabilidade da precipitação na américa do sul forçada com diferentes parametrizações de superfície para previsão de curto prazo, Anais ... Congresso Brasileiro de Meteorologia, 2010.

KOUSKY, V.E.; CHU, P.S. Fluctuations in annual rainfall for northeast Brazil, Journal of The Meteorological Society of Japan, v. 56, p. 457-466, 1978.

MANN, M.E.; PARK, J.; BRADLEY, R.S. Global interdecadal and century-scale climate oscillations during the past 5 centuries, Nature, v. 378, p. 266-270, 1995.

MANTUA, N.J.; HARE, S. R.; ZHANG, Y.; WALLACE, J.M.; FRANCIS, R.C. A Pacific interdecadal climate oscillation with Impacts on salmon production, Bulletin American Meteorolical Society, v. 78, p. 1069-1079, 1997.

MARCELINO, E.V. Desastres Naturais e Geotecnologias: Conceitos Básicos. INPE, São José dos Campos, 2008, Disponível

em http://mtc-m18.sid.inpe.br/col/sid.inpe.br/mtc-m18@80/20 08/07.02.16.22/doc/publicacao.pdf. Acesso em 01-12-2014.

MARKHAM, C.G. Apparent periodicities in rainfall at Fortaleza, Ceará, Brazil. Journal of Applied Meteorology and Climatology, v. 13, p. 176-179, 1974.

MOLION, L.C.B. Aquecimento global, el Niños, manchas solares, vulcões e oscilação decadal do Pacífico. Revista Climanálise, Cachoeira Paulista, v. 3, n. 1, p. 1-5, ago. 2005.

MORETTIN, P.A. Ondas e Ondeletas: Da Análise de Fourier à Análise de Ondeletas, EDUSP, 193 P., 1999. 
MOURA, A.D.; KAYANO, M.T. A Distribuição da precipitação para os anos extremosdo nordeste do Brasil, Revista Brasileira de Meteorologia, v. 7, p. 7-9, 1986.

NOBRE, C.A.; MOLION, L.C.B. The Climatology of Droughts and Droughts Prediction, In: Impacts of Climatic Variation on Agriculture, v. 2: Assessements in semi-arid regions, M. P. PARRY, T.R. CARTER, N.T. KONIJIN (eds.), D. Reidel Pub. Co., p. 764, 1987.

NCEM - North Carolina Division of Emergency Management. Local hazard mitigation planning manual. Raleigh: NCEM/UC, 90 p., 1998.

POLZIN, D.; HASTENRATH, S. Climate of Brazil's Nordeste and Tropical Atlantic Sector: Preferred Time scales of variability. Revista Brasileira de Meteorologia, v. 29, n. 2, p. 153-160, 2014.

REPELLI, C.A.; FERREIRA, N.S.; ALVES, J.M.B.; NOBRE, C.A. Índice de anomalia de precipitação para o Estado do Ceará. In: Anais do X Congresso Brasileiro de Meteorologia, 1998, Brasília DF., 1998.

ROBOCK, A.; MAO, J. The volcanic signal in surface temperature observations. Journal of Climate, v. 8, n. 5, p. 10861103, 1995.

ROBOCK, A.; FREE, M.P. Ice cores as an index of global volcanism from 1850 to the present. Journal of Geophysical Research: series D, Washington, DC, v. 100, n. 6, p. 1154911568, 1995.

ROCKWOOD, A.A.; MADDOX, R.A. Mesoscale and synoptic scale interactions leading to intense convection: The case of 7 June 1982. Weather and Forecasting, v. 3, n. 1, p. 51-68, 1988.

SANTOS, C.A.C.; BRITO, J.I.B. Análise dos índices de extremos para o semi-árido do Brasil e suas relações com TSM e IVDN. Revista Brasileira de Meteorologia, v. 22, n. 3, p. 303-312, 2007.

Santos, C.A.C.; Neale, C.M.U.; Rao, T.V.R.; Silva, B.B. 2011. Trends in indices for extremes in daily temperature and precipitation over Utah, USA. International Journal of Climatology, v. 31, p. 1813-1822, 2011.
SANTOS, C.A.C. Recent changes in temperature and precipitation extremes in an ecological reserve in federal district, Brazil. Revista Brasileira de Meteorologia, v. 29, n. 1, p. 13-20, 2014.

SCHNEIDER M.; VITORINO, M.I.; SILVA DIAS, P.L. Monitoramento da intrasazonalidade por meio da transformada em ondeletas, Anais do Simpósio Internacional de Climatologia..., Fortaleza, 2005.

SERVAIN, J. Simple climatic indices for the tropical Atlantic Ocean and some applications, Journal of Geophysical Research, v. 96, p. 15137-15146, 1991.

SOUZA, E. B.; BRABO ALVES, J. M.; NOBRE, P. Anomalias de precipitação nos setores norte e leste do Nordeste brasileiro em associação aos eventos do padrão de dipolo observados na bacia do atlântico tropical. Revista Brasileira de Meteorologia, v. 13, n. 2, p. 45-55, 1998.

TORRENCE, C.; COMPO, G.P.: A practical guide to wavelet analysis. Bulletin of the American Meteorological Society, v. 79, p. 61-78, 1998.

TORRENCE, C.; WEBSTER, P.J. Interdecadal changes in the ENSO-monsoon system. Journal of Climate, v. 12, p. 2679-2690, 1999.

TRIGO, R.M.; GALVÃO, C.O. ; TRIGO, I.F. Aplicação de wavelets ao estudo da variabilidade de caudais diários: uma comparação entre algumas bacias portuguesas e brasileiras. Anais... IV Simpósio de Hidráulica e Recursos Hídricos dos Países de Língua Oficial Portuguesa, 1999, APRH, Coimbra, p. 1-15.

VITORINO, M.I. Análise das Oscilações Intrasazonais sobre a América do Sul e Oceanos Adjacentes Utilizando a Análise de Ondeletas, 2003, 147 p. Tese de Doutorado em Meteorologia, INPE, São José dos Campos, 2003.

WENG, H.; LAU, K-M. Wavelets, period doubling, and timefrequency localization with application to organization of convection over the Tropical Western Pacific. Journal of the Atmospheric Sciences, v. 51, n. 17, p. 2523-2541, 1994.

This is an Open Access article distributed under the terms of the Creative Commons Attribution Non-Commercial License which permits unrestricted non-commercial use, distribution, and reproduction in any medium provided the original work is properly cited. 